\title{
DESIGN AND USE OF ORGANIC NANOPARTICLES PREPARED FROM STAR-SHAPED POLYMERS WITH REACTIVE END GROUPS
}

Lieven M. Van Renterghem ${ }^{1}$, Mieke Lammens ${ }^{1}$, Bart Dervaux ${ }^{1}$, Pascal Viville ${ }^{2 \sharp}$, Roberto Lazzaroni $^{2}$, Filip E. Du Prez, ${ }^{1 *}$

${ }^{1}$ Department of Organic Chemistry, Polymer Chemistry Research Group Ghent University, Krijgslaan 281 S4-bis, B-9000 Ghent, Belgium

${ }^{2}$ Laboratory for Chemistry of Novel Materials, Université de Mons, Place du Parc 20, B-7000 Mons, Belgium

\# Present address: Materia Nova, Parc Initialis, Avenue Nicolas Copernic 1, B-7000 Mons, Belgium

Correspondence to: Filip E. Du Prez, Ghent University, Department of Organic Chemistry, Polymer Chemistry Research Group, Krijgslaan 281 S4, 9000 Ghent, Belgium E-mail : Filip.Duprez@UGent.be

Fax: +3292644972

Tel: +329264 4503 


\begin{abstract}
Star-shaped poly(isobornyl acrylate) (PiBA) was prepared by atom transfer radical polymerization (ATRP) using multifunctional initiators. The optimal ATRP-conditions were determined to minimize star-star coupling and to preserve high end group functionality ( $>90 \%)$. Star-shaped PiBA with narrow polydispersity index was synthesized with 4, 6 and 12 arms and of varying molecular weight (10000 to $100000 \mathrm{~g} \cdot \mathrm{mol}^{-1}$ ) using 4 equivalents of a $\mathrm{Cu}(\mathrm{I}) \mathrm{Br} / \mathrm{PMDETA}$ catalyst system in acetone. Matrix-assisted laser desorption/ionization time-of-flight (MALDITOF) analysis, NMR spectroscopy and size exclusion chromatography (SEC) confirmed their controlled synthesis. The bromine-end group of each arm was then transformed to a reactive end group by a nucleophilic substitution with methacrylic acid or cinnamic acid (conversion $>90 \%$ ). These reactive star polymers were used to prepare PiBA-nanoparticles by intramolecular polymerization of the end groups. The successful preparation of this new type of organic nanoparticles on a multi-gram scale was proven by NMR spectroscopy and SEC. Subsequently, they have been used as additives for linear, rubbery poly( $n$-butyl acrylate). Rheology measurements indicated that the viscoelastic properties of the resulting materials can be finetuned by changing the amount of incorporated nanoparticles (1-20 wt\%), as a result of the entanglements between the nanoparticles and the linear polymers.
\end{abstract}

Keywords: star polymers, ATRP, poly(isobornyl acrylate), reactive end groups, nanoparticles 


\section{Introduction}

Because of their remarkable properties, star polymers continue to attract attention in polymer research $^{1,2}$. In comparison to their linear analogues, star polymers have different rheological and mechanical properties and exhibit higher degrees of end group functionality. Controlled synthesis of star polymers also contributes to the elucidation of structure-property relationships in polymer science. Recent developments in atom transfer radical polymerization (ATRP) and reversible addition-fragmentation chain-transfer polymerization (RAFT) made it possible to use radical polymerization for the controlled synthesis of star polymers ${ }^{3-5}$. For these techniques, a variety of multifunctional initiators has been developed and successfully used ${ }^{6-15}$.

Although end group reactive star polymers offer interesting perspectives to a number of applications such as a novel route to nanoparticles, nanocontainers or nanoporous layers, ${ }^{16-20}$ only a limited amount of work has been done on the synthesis of such reactive stars. Gnanou et al. described six arm poly(ethylene oxide) (PEO) stars, carrying pyridyl, pyridinium or hydroxyl end groups, ${ }^{21}$ and 6 arm polystyrene (PS) with allyl, hydroxyl and hexafullerene end groups ${ }^{22}$. The latter can be used in the context of "smart" materials, whereas the hydroxyl functions can be used to prepare star-block copolymers (e.g. star(PS-b-PEO) 6 ). Recently, we described the synthesis of star-shaped poly(tetrahydrofuran) with allyl and hydroxyl end groups ${ }^{23}$.

In this work, we aimed at the preparation of reactive star-shaped polymers by ATRP as precursors for a new type of nanoparticle. Generally, particles with sizes ranging from $50 \mathrm{~nm}$ to several micrometers are easily accessible with micro- and mini-emulsion polymerization techniques ${ }^{24,25}$. However, the preparation of smaller nanoparticles is more challenging. One route is the chemical fixation of self-assembled micellar structures based on block copolymers, as for example described by Wooley and others ${ }^{26-30}$. Another approach is to prepare unimolecular particles by intramolecular cross-linking. For example, Miller et al. described different 
copolymers with functional groups, which led to nanoparticles with sizes ranging from 3 to 15 $\mathrm{nm}$ by intramolecular self-crosslinking under high dilution conditions ${ }^{19,20,31}$. Zimmerman et al. synthesized chain-functionalized star polymers, from which nanosized "cored" star polymers can be created after removal of the multifunctional initiator ${ }^{16}$.

Our approach was to use an intramolecular cross-linking process to create unimolecular nanoparticles (see Scheme 1). Therefore, multifunctional initiators developed by Heise et al. ${ }^{8,9}$ have been used to prepare star-shaped poly(isobornyl acrylate) by ATRP in a controlled way. In a second step, the bromine end groups are transformed to a reactive end group by a nucleophilic substitution with methacrylic acid. The resulting reactive star polymers are then transformed to unimolecular nanoparticles by an intramolecular polymerization.
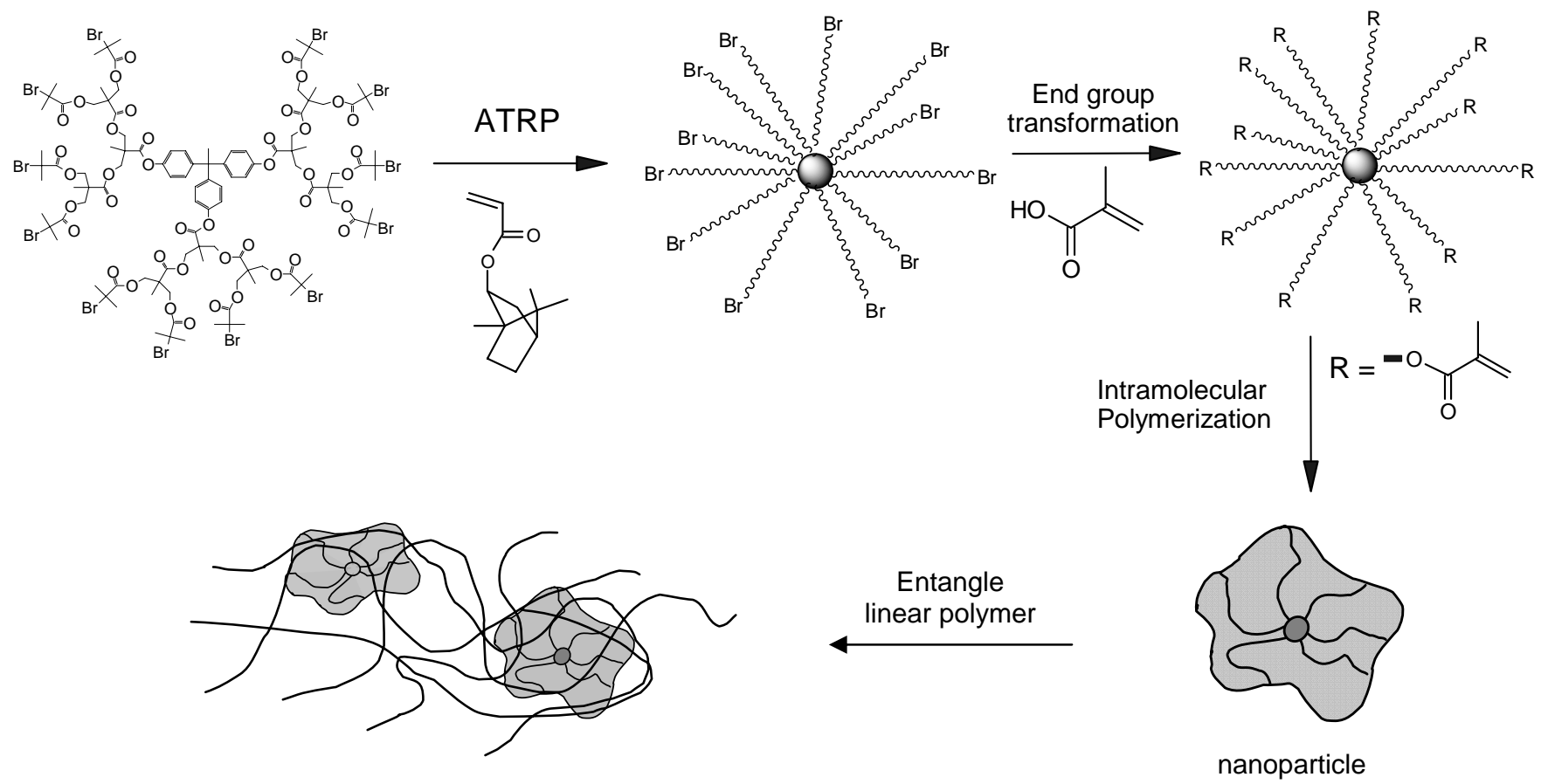

Scheme 1: General scheme for the preparation of poly(isobornyl acrylate) nanoparticles and the subsequent incorporation of a linear polymer. 
Finally, we investigated the use of such nanoparticles as non-covalent crosslinkers for linear polymers (see Scheme 1). In this way we aimed at the creation of similar properties as those of thermoplastic elastomers (TPE's) without having to prepare triblock copolymers ${ }^{32}$. As a model system, we investigated the viscoelastic properties of a material in which linear, rubbery poly $(n-$ butyl acrylate) (PnBuA) chains are entangled with a variable amount of the organic nanoparticles. 


\section{Experimental}

\section{Materials.}

Isobornyl acrylate (iBA, Aldrich, tech.) was purified by vacuum distillation $\left(121^{\circ} \mathrm{C} / 18 \mathrm{mmHg}\right)$. n-Butyl acrylate (nBuA, Aldrich, >99\%) was purified by distillation. $\mathrm{Cu}(\mathrm{I}) \mathrm{Br}$ (Aldrich, $98 \%$ ) was purified by stirring with acetic acid, then by filtering and washing with methanol, and finally by drying in a vacuum oven at $70{ }^{\circ} \mathrm{C} . N, N, N^{\prime}, N^{\prime \prime}, N^{\prime \prime}$-pentamethyldiethylenetriamine (PMDETA, Acros, $99+\%)$ was distilled $\left(85-86^{\circ} \mathrm{C} / 12 \mathrm{mmHg}\right)$. Solvents were purchased from Aldrich (HPLC grade) and used without purification.

Trans-2-[3-(4-tert-butylphenyl)-2-methyl-2-propenylidene]malononitrile (BMPM), methacrylic acid, 1,8-diazobicyclo[5,4,0]undec-7-ene (DBU), benzoin, $\mathrm{Cu}(\mathrm{II}) \mathrm{Br}_{2}$ and 2,2'-Azobis(2methylpropionitrile) (AIBN) were purchased from Aldrich or Acros and used as received.

\section{Methods of analysis}

${ }^{1} \mathrm{H}-\mathrm{NMR}$ spectra were recorded in $\mathrm{CDCl}_{3}$ at room temperature on a Bruker AM500 spectrometer at $500 \mathrm{MHz}$ or on a Bruker Avance 300 at $300 \mathrm{MHz}$ with tetramethylsilane as internal standard. Size exclusion chromatography (SEC) was performed on a Waters instrument, with a refractive index (RI) detector (2410 Waters), equipped with Waters Styragel HR3, HR4 and HR5 serial columns (5 micron particle size) at $35^{\circ} \mathrm{C}$. Polystyrene standards were used for calibration and $\mathrm{CHCl}_{3}$ was used as an eluent at a flow rate of $1.5 \mathrm{ml} / \mathrm{min}$. Molecular weight and polydispersity index were determined using the Breeze Millennium software.

SEC with triple detection (refractive index (RI), viscosity and light scattering) was performed on an instrument equipped with two Styragel (mixed C) columns at $40^{\circ} \mathrm{C}$. Polystyrene standards were used for calibration and THF was used as an eluent at a flow rate of $1.0 \mathrm{ml} / \mathrm{min}$. A Viscotec 
TS10-detector (scattering angle: $90^{\circ}$, wavelength laser: $670 \mathrm{~nm}$ ) was used in combination with an Knaub RI-detector. Molecular weight and polydispersity index were determined using the Trisec software $($ Viscotec, $\mathrm{dn} / \mathrm{dc}=0.103)$.

MALDI-TOF mass spectra were recorded on an Applied Biosystems Voyager DE STR MALDITOF spectrometer equipped with $2 \mathrm{~m}$ linear and $3 \mathrm{~m}$ reflector flight tubes and a $337 \mathrm{~nm}$ nitrogen laser ( $3 \mathrm{~ns}$ pulse). All mass spectra were obtained with an accelerating potential of $20 \mathrm{kV}$ in positive ion mode and in linear and/or reflector mode. BMPM (20 mg/ml in THF) was used as a matrix, sodium trifluoroacetate $(1 \mathrm{mg} / \mathrm{ml})$ was used as a cationating agent, and polymer samples were dissolved in THF $(2 \mathrm{mg} / \mathrm{ml})$. Analyte solutions were prepared by mixing $10 \mu \mathrm{L}$ of the matrix, $5 \mu \mathrm{L}$ of the salt, and $5 \mu \mathrm{L}$ of the polymer solution. Subsequently, $0.5 \mu \mathrm{L}$ of this mixture was spotted on the sample plate, and the spots were dried in air at room temperature. A poly(ethylene oxide) standard $\left(\mathrm{M}_{\mathrm{n}}=2000 \mathrm{~g} \cdot \mathrm{mol}^{-1}\right.$ or $\left.5000 \mathrm{~g} \cdot \mathrm{mol}^{-1}\right)$ was used for calibration. All data were processed using the Data Explorer (Applied Biosystems) and the Polymerix (Sierra Analytics) software package.

Rheology measurements were performed with a Bohlin Instruments CS50 (controlled stress) rheometer. A plate-plate configuration was used $(10 \mathrm{~mm})$ with a distance of $1 \mathrm{~mm}$ between the two plates.

Samples for atomic force microscopy analysis (AFM) were prepared by solvent casting at ambient conditions starting from solutions of the star polymers in THF. Typically, $20 \mu 1$ of a dilute solution (0.1 to $0.001 \mathrm{wt} \%)$ was cast on a $1 \mathrm{x} 1 \mathrm{~cm}^{2}$ freshly-cleaved highly-oriented pyrolytic graphite (HOPG) substrate. The samples were analyzed after complete evaporation of the solvent at room temperature. All AFM images were recorded in air with a Nanoscope IIIa microscope operated in tapping mode (TM). The probes were commercially available silicon tips 
with a spring constant of $24-52 \mathrm{~N} / \mathrm{m}$, a resonance frequency lying in the $264-339 \mathrm{kHz}$ range, and a typical radius of curvature in the $10-15 \mathrm{~nm}$ range. Both the topography and the phase signal images were recorded with the highest sampling resolution available, i.e., $512 \times 512$ data points.

\section{Synthesis of the initiators}

For the synthesis of the initiators, we refer to the literature ${ }^{8,9,33,34}$. The structure of the initiator with 12 bromine groups is shown in Scheme 1.

\section{Synthesis of star-shaped PiBA}

A typical polymerization procedure is as follows (e.g., for PiBA_12A_10): the initiator (with 12 bromine groups, $0.495 \mathrm{~g}$; $0.16 \mathrm{mmol})$ was dissolved in $10.0 \mathrm{ml}$ acetone. $30 \mathrm{ml}(142 \mathrm{mmol})$ of iBA was added, followed by $1.58 \mathrm{ml}(7.57 \mathrm{mmol})$ PMDETA. The mixture was degassed by three freeze-pump-thaw cycles after which the catalyst $(\mathrm{Cu}(\mathrm{I}) \mathrm{Br}: 1.03 \mathrm{~g}, 7.2 \mathrm{mmol} \& \mathrm{Cu}(\mathrm{II}) \mathrm{Br}: 0.08 \mathrm{~g}$, $0.38 \mathrm{mmol}$ ) was added under a constant nitrogen flow. The mixture was homogenized by stirring at room temperature for $15 \mathrm{~min}$. The reaction flask was then immersed in an oil bath thermostated at $65{ }^{\circ} \mathrm{C}$. Samples were withdrawn periodically to monitor the monomer conversion (by NMR spectroscopy) and the average molecular weight (by SEC). The reaction was ended by cooling the reaction mixture in liquid nitrogen. The reaction mixture was then diluted in THF, and the copper was removed by passing the diluted reaction mixture through a column of neutral $\mathrm{Al}_{2} \mathrm{O}_{3}$. The solvent was evaporated until a viscous solution was obtained, and the polymer was precipitated in cold methanol (10-fold excess) and filtered off. The resulting polymer was dried in vacuum (yield: 22\%). A detailed NMR-analysis is added in the supporting information. 


\section{End group transformation of PiBA}

A typical procedure is as follows (e.g., for PiBA_12A_10_MA_1): $5 \mathrm{~g}$ star shaped polymer with 12 bromine groups ( $1.15 \mathrm{mmol}$ bromine groups) was dissolved in $60 \mathrm{ml}$ ethyl acetate (EtOAc) in a dry flask under nitrogen atmosphere. To this solution $0.59 \mathrm{ml}(6.9 \mathrm{mmol})$ of methacrylic acid and $1.03 \mathrm{ml} \mathrm{DBU}(6.9 \mathrm{mmol})$ was added. The reaction was stirred for 4 days at $50^{\circ} \mathrm{C}$. The solvent was evaporated until a viscous solution was obtained, and the polymer was precipitated in cold methanol (10-fold excess) and filtered off. The resulting polymer was dried in vacuum (yield: $>95 \%)$.

\section{Transformation of reactive star shaped PiBA to nanoparticles}

The intramolecular polymerization of the reactive star polymers was typically performed as follows (12A_10_UV_4, Table 3): $1 \mathrm{~g}$ star shaped polymer with 12 methacrylate groups $(0.24$ mmol methacrylate groups) was dissolved in $250 \mathrm{ml}$ toluene in a dry flask under nitrogen atmosphere. The reaction mixture was degassed under vacuum and $13 \mathrm{mg}(0.06 \mathrm{mmol})$ of benzoin was added. The flask was placed under a UV-lamp (900W Hg-lamp $\left.\left(16 \mathrm{~mW} / \mathrm{cm}^{2}\right)\right)$ for 4 hours under stirring. The solvent was then evaporated until a viscous solution was obtained, and the polymer was precipitated in cold methanol (10-fold excess) and filtered off. The resulting polymer was dried in vacuum (yield: $>95 \%$ ).

\section{Modification of PnBuA with nanoparticles}

First, a solution of the monomer $(\mathrm{nBuA})$ with $0.5 \mathrm{wt} \%$ of AIBN initiator was prepared and degassed by bubbling with $\mathrm{N}_{2}$. Subsequently, $2 \mathrm{ml}$ of this mixture was transferred to a little flask with the desired amount of nanoparticles. The flasks were placed under nitrogen and 
polymerization was started by heating to $90^{\circ} \mathrm{C}$. After 12 hours of reaction, the materials were dried for 24 hours in vacuum. 


\section{Results and discussion}

Star-shaped PiBA by ATRP

As depicted in Scheme 1, the first step consisted of the preparation of star-shaped poly(isobornyl acrylate) (PiBA). ATRP was chosen as the polymerization technique for two reasons. First, by choosing the right reaction conditions, star-shaped polymers can be prepared in a controlled way with a minimal extent of star-star coupling ${ }^{6-15}$. Secondly, after ATRP of acrylates, a secondary bromine end group is available at the end of each arm of the stars for further conversion into reactive groups. PiBA has been selected as the polyacrylate for its high $\mathrm{T}_{\mathrm{g}}$ value $\left(94^{\circ} \mathrm{C}\right)$, which facilitates the characterization and the use of the subsequently formed nanoparticle.

For the preparation of multifunctional initiators with 4,6 and 12 bromine end groups on a multigram scale, a synthetic route developed by Heise et al., which is based on the repetition of a few esterification reactions, was used (See Scheme 1 for the structure of the initiator with 12 bromine groups) ${ }^{9,35}$.

First, the reaction conditions for the controlled ATRP-synthesis of linear PiBA were determined (see Table 1). By using 4 equivalents of $\mathrm{Cu}(\mathrm{I}) \mathrm{Br}$ and $\mathrm{N}, \mathrm{N}^{\prime}, \mathrm{N}^{\prime}, \mathrm{N}^{\prime \prime}, \mathrm{N}^{\prime \prime}-$ pentamethyldiethylenetriamine (PMDETA) as ligand, in acetone as solvent, linear PiBA was obtained with low polydispersity index $\left(\mathrm{M}_{\mathrm{w}} / \mathrm{M}_{\mathrm{n}}, \mathrm{PDI}\right)$ and a controlled molecular weight. The difference between the theoretical average molar mass $\left(\mathrm{M}_{\mathrm{n}, \text { theo }}\right)$ and the molar mass determined by $\operatorname{SEC}\left(\mathrm{M}_{n, \mathrm{SEC}}\right)$ can be explained by the fact that linear poly(styrene) standards were used for the calibration. However, the $\mathrm{M}_{\mathrm{n}}$-values determined by MALDI-TOF were in good correlation with the theoretical values (e.g. $\mathrm{M}_{\mathrm{n}, \mathrm{MALDI}}$ for PiBA_2 was $9800 \mathrm{~g} \cdot \mathrm{mol}^{-1}$ and $7500 \mathrm{~g} \cdot \mathrm{mol}^{-1}$ for PiBA_3). The reaction conditions for linear PiBA have then been used for the preparation of star-shaped PiBA. An overview of series of synthesized star polymers (12,6 and 4 arms) and their corresponding reaction conditions are shown in Table 1. The polymerizations for which 4 
equivalents of $\mathrm{Cu}(\mathrm{I}) \mathrm{Br}$ and PMDETA were used always resulted in star-shaped polymers with controlled molecular weight and low $\mathrm{M}_{\mathrm{w}} / \mathrm{M}_{\mathrm{n}}$-values. These reaction conditions are also highly reproducible (compare for example PiBA_12A_10 and PiBA_12A_11). When more solvent is added to the reaction (PiBA_12A_15, 50V\% acetone) the reaction slows down, as expected. With $25 \mathrm{v} \%$ of acetone, there is an optimal balance between the speed and the control of the reaction. Most reactions were carried out with a theoretical degree of polymerization (DP) of 75 per arm. However, by adapting the reaction conditions (higher temperature or longer reaction time), higher DP's can be reached (e.g., PiBA_12A_7).

In general, quite low $M_{w} / M_{n}$-values were obtained and the experimental $M_{n}$ values are in good correlation with the theoretical values. Because of the smaller hydrodynamic volume of branched structures in comparison to linear analogues, $\mathrm{M}_{\mathrm{n}}$-values of the stars measured by SEC, calibrated with linear standards using an RI-detector, are not absolute ${ }^{1}$. However, if a SEC system with triple detection (refractive index, viscosity and light scattering) is used, absolute values that are in good correlation with the theoretical values can be obtained (Table 1). 
Table 1: Experimental results for the synthesis of linear and star-shaped poly(isobornyl acrylate).

\begin{tabular}{|c|c|c|c|c|c|c|c|}
\hline Code & $\begin{array}{l}\text { Number } \\
\text { of arms }\end{array}$ & {$[\mathbf{I n}]_{0} /[\mathrm{Cu}(\mathrm{I})]_{0} /[\mathrm{L}]$} & $\begin{array}{l}\text { Time } \\
\text { (min) }\end{array}$ & $\begin{array}{c}\text { Conv. } \\
(\%)\end{array}$ & $\underset{\left(g_{n} \cdot m^{\prime} l^{-1}\right)}{M_{\text {theo }}}$ & $\begin{array}{l}M_{n, S E C}{ }^{(c)} \\
\left(g \cdot \mathbf{m o l}^{-1}\right)\end{array}$ & $\mathbf{M}_{\mathrm{w}} / \mathbf{M}_{\mathbf{n}}$ \\
\hline PiBA_1 ${ }^{\text {(a) }}$ & linear & $1 / 2 / 2$ & 1100 & 37 & 5900 & 4100 & 1.07 \\
\hline PiBA_2 ${ }^{\text {(a) }}$ & linear & $1 / 4 / 4$ & 250 & 65 & 10300 & 6500 & 1.27 \\
\hline PiBA_3 ${ }^{(b)}$ & linear & $1 / 4 / 4$ & 240 & 46 & 7400 & 5300 & 1.11 \\
\hline PiBA_12A_1 & 12 & $1 / 1.5 / 1.5$ & 360 & 8 & 18000 & 9600 & 1.15 \\
\hline PiBA_12A_2 & 12 & $\begin{array}{c}1 / 4 / 4 \\
+5 \% \mathrm{Cu}(\mathrm{II}) \mathrm{Br})\end{array}$ & 1260 & 95 & 182000 & 84000 & 1.35 \\
\hline PiBA_12A_3 & 12 & $1 / 4 / 4$ & 141 & 26 & 52000 & $\begin{array}{l}23000 \\
59200^{\mathrm{d}}\end{array}$ & 1.14 \\
\hline PiBA_12A_4 & 12 & $\begin{array}{c}1 / 4 / 4 \\
+5 \% \mathrm{Cu}(\mathrm{II})\end{array}$ & 125 & 21 & 42000 & 21000 & 1.10 \\
\hline PiBA_12A_5 & 12 & $\begin{array}{c}1 / 4 / 4 \\
+5 \% \mathrm{Cu}(\mathrm{II})\end{array}$ & 135 & 30 & 59000 & $\begin{array}{l}24600 \\
63000^{\mathrm{d}}\end{array}$ & 1.09 \\
\hline PiBA_12A_6 & 12 & $\begin{array}{c}1 / 4 / 4 \\
+5 \% \mathrm{Cu}(\mathrm{II})\end{array}$ & 90 & 16 & 34000 & $\begin{array}{l}25500 \\
40000^{\mathrm{d}}\end{array}$ & 1.06 \\
\hline PiBA_12A_7 ${ }^{(\mathrm{e})}$ & 12 & $1 / 4 / 4$ & 185 & 22 & 85500 & $\begin{array}{c}39500 \\
104000^{\mathrm{d}}\end{array}$ & 1.14 \\
\hline PiBA_12A_10 & 12 & $1 / 4 / 4$ & 100 & 22 & 44000 & $\begin{array}{l}22000 \\
52000^{\mathrm{d}}\end{array}$ & 1.07 \\
\hline PiBA_12A_11 & 12 & $1 / 4 / 4$ & 100 & 23 & 47000 & $\begin{array}{l}24000 \\
56000^{\mathrm{d}}\end{array}$ & 1.08 \\
\hline PiBA_12A_15 ${ }^{(\mathrm{f})}$ & 12 & $\begin{array}{c}1 / 4 / 4 \\
+5 \% \mathrm{Cu}(\mathrm{II})\end{array}$ & 116 & 7 & 17000 & 6600 & 1.05 \\
\hline PiBA_12A_17 $7^{(\mathrm{g})}$ & 12 & $1 / 4 / 4$ & 275 & 69 & 134000 & $\begin{array}{c}71600 \\
139400^{\mathrm{d}}\end{array}$ & 1.16 \\
\hline PiBA_6A_1 & 6 & $1 / 4 / 4$ & 270 & 17 & 17100 & 12800 & 1.06 \\
\hline PiBA_6A_2 & 6 & $1 / 4 / 4$ & 239 & 23 & 22900 & 17600 & 1.06 \\
\hline PiBA_6A_3 & 6 & $1 / 4 / 4$ & 120 & 14 & 15000 & $\begin{array}{l}14200 \\
15700^{\mathrm{d}}\end{array}$ & 1.09 \\
\hline PiBA_6A_5 & 6 & $1 / 4 / 4$ & 120 & 15 & 16800 & 14200 & 1.09 \\
\hline PiBA_4A_2 & 4 & $1 / 4 / 4$ & 1254 & 46 & 29500 & 23700 & 1.15 \\
\hline PiBA_4A_3 & 4 & $1 / 4 / 4$ & 90 & 11 & 7600 & $\begin{array}{l}7000 \\
8000^{d}\end{array}$ & 1.08 \\
\hline
\end{tabular}

Reactions performed at $\mathrm{T}=50^{\circ} \mathrm{C}, 25 \mathrm{~V} \%$ of acetone and $\mathrm{DP}_{\text {theo }}=75$.

$[\mathrm{In}]_{0} /[\mathrm{Cu}(\mathrm{I})]_{0} /[\mathrm{L}]=$ ratio initiator $/ \mathrm{Cu}(\mathrm{I}) \mathrm{Br} /$ ligand 
${ }^{\text {(a) }}$ methyl-2-bromopropionate was used as initiator; ${ }^{(b)}$ ethyl- $\alpha$-bromoisobutyrate was used as initiator; ${ }^{\left({ }^{(c)}\right.}$ determined via $\mathrm{SEC}$ in $\mathrm{CHCl}_{3}$ using linear PS-standards; ${ }^{(\mathrm{d})}$ absolute $\mathrm{M}_{\mathrm{n}}$ determined via $\mathrm{SEC}$ with triple detection; ${ }^{(\mathrm{e})} \mathrm{DP}_{\text {theo }}=$ $100 ;{ }^{(\mathrm{f})}$ reaction performed in $50 \mathrm{~V} \%$ of acetone; ${ }^{(\mathrm{f})} \mathrm{T}=65^{\circ} \mathrm{C}$.

The good control over the reaction was also proven by kinetic studies. This is illustrated in Figure 1 for PiBA_12A_3. Under the chosen reaction conditions, the semi-logarithmic first-order plot shows a linear behavior, indicating that the polymerization is first-order with respect to the monomer concentration and that the concentration of the growing radicals remains constant during the polymerization. Also, a linear increase of $M_{\mathrm{n}}$ with the monomer conversion is observed and the PDI's are low. However, it has to be mentioned that above conversions of about $50 \%$, star-star coupling occurs due to termination reactions. This is illustrated in Figure 2 in which the SEC curves are depicted as a function of reaction time for the synthesis of star-shaped PiBA with 12 arms. It is clear that for a reaction time of 35 minutes (9\% conversion) and 115 minutes $(27 \%$ conversion) star-star coupling is absent and no shoulders at high molecular weight are observed. However, if the reaction is continued to higher conversions ( $21 \mathrm{~h}, 97 \%$ conversion), the radical concentration in the reaction mixture increases and termination reactions are more prevalent, which leads to star-star coupling and a less defined structure. This phenomenon is inherent of the preparation of star-shaped polymers by ATRP, however, it can be controlled by terminating the polymerizations at sufficiently low conversion ${ }^{12,14,36}$. 

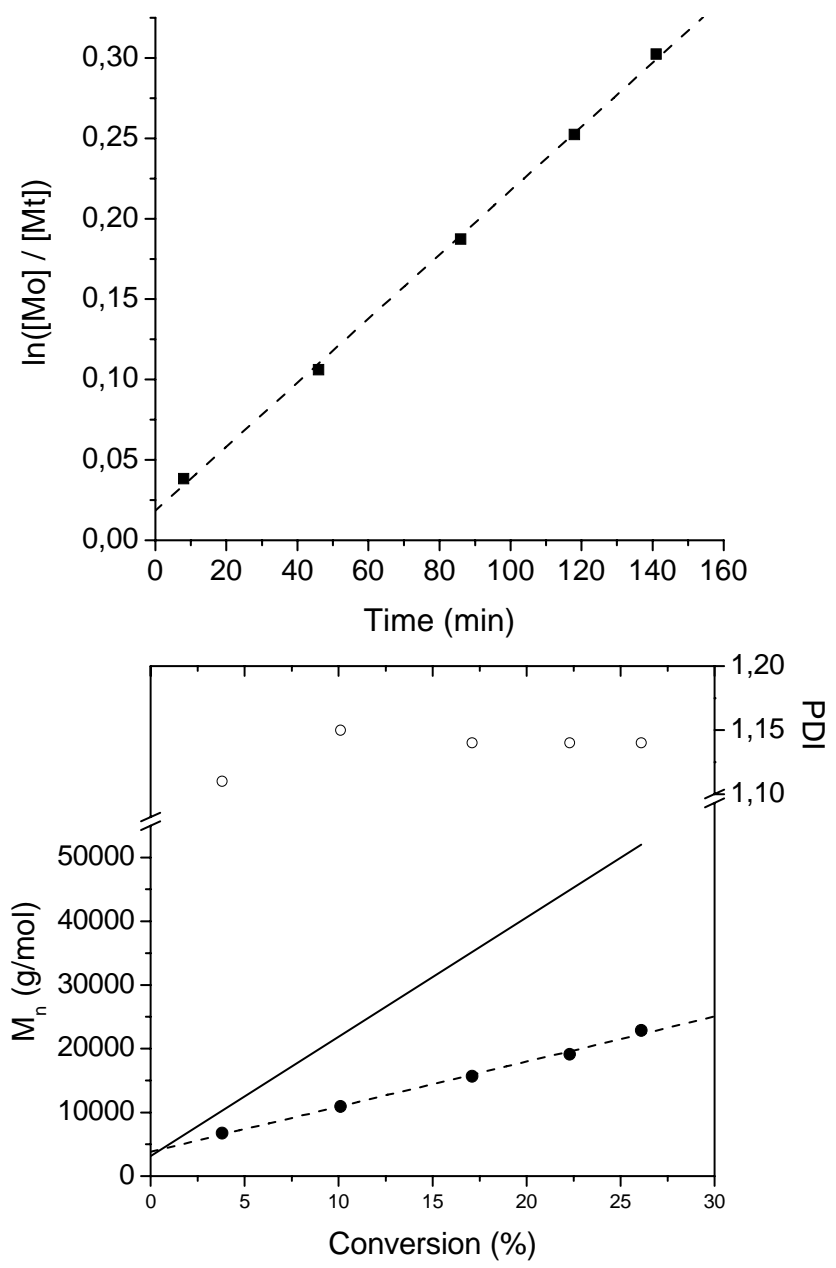

Figure 1: Kinetics for PiBA_12A_3. Top: first order kinetics. Bottom: evolution of $\mathrm{M}_{\mathrm{n}}, \mathrm{SEC}$ and $\mathrm{M}_{\mathrm{w}} / \mathrm{M}_{\mathrm{n}}(\mathrm{O})$ with conversion. — : theoretical curve, - - - : best fitting straight line. 


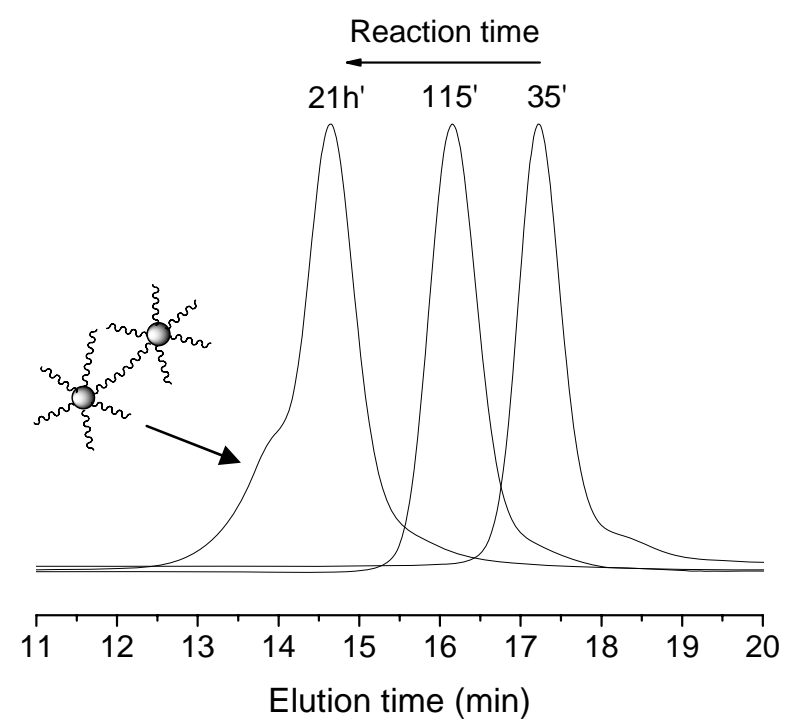

Figure 2: SEC curves as a function of reaction time for star-shaped PiBA with 12 arms (PiBA_12A_2).

In addition to SEC with triple detection, MALDI-TOF has also been used to determine the exact molecular weight of the star polymers. Due to a difficult ionization process, it is difficult to measure polymer samples with high molecular weights, in particular when complex architectures such as star-shaped polymers need to be analyzed. Furthermore, there is to our knowledge no example of a MALDI-TOF analysis of a PiBA-based polymer in literature. Hence, it was a tedious process to determine the optimal experimental conditions for the analysis of the starshaped PiBA. An example of a MALDI-TOF spectrum is shown in Figure 3 for a star polymer with 12 arms. Two distributions can be observed: the first one, the main distribution, can be attributed to the $\mathrm{Na}^{+}$-adduct of the star-shaped PiBA $\left([\mathrm{M}+\mathrm{Na}]^{+}\right)$. The second distribution can be attributed to the adduct of two star polymer molecules with one sodium-cation. This is a typical phenomenon for the MALDI-analysis of structures with a high $\mathrm{M}_{\mathrm{n}}{ }^{37,38}$. However, it cannot be excluded that part of the signal is caused by some star-star coupling reactions during ATRP. From the main distribution, the molecular weight of the sample can be calculated. The values 
obtained were always in good agreement with those determined by SEC $\left(M_{n}=62000 \mathrm{~g} \cdot \mathrm{mol}^{-1}\right.$ for PiBA_12A_3).

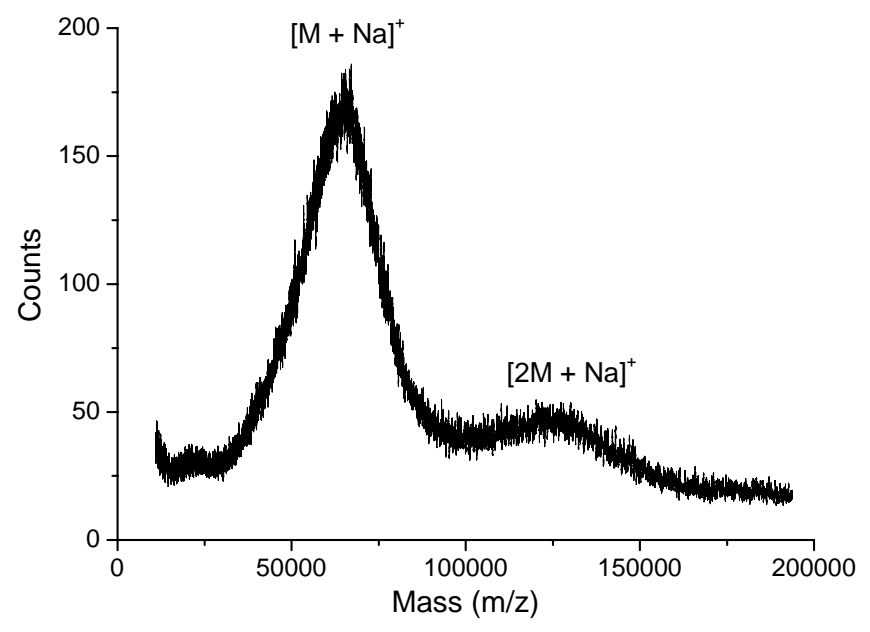

Figure 3: MALDI-TOF mass spectra of PiBA_12A_3.

To estimate the size of individual star-shaped polymer molecules, atomic force microscopy (AFM) analysis was carried out on a high molecular weight system (PiBA_12A_7, Figure 4). When preparing the samples from dilute solutions (e.g., $0.05 \mathrm{wt} \%$ in THF), a single layer of individual bright objects is observed, both on the height and on the phase images. These objects are single polymer molecules. A few larger structures are also seen, which are probably caused by aggregation during the AFM sample preparation or by some covalently coupled stars (see earlier). The average size of the particles was measured to be $12 \mathrm{~nm}$. For a fully stretched PiBA_12A_7 star molecule, a diameter of about $27 \mathrm{~nm}$ can be calculated. The value obtained by AFM thus indicates that some coiling of the arms takes place, as expected. Such coiling may also explain why individual arms cannot be distinguished in the AFM images.

The fact that single molecules can be observed also indicates a low degree of intermolecular entanglements of the chains as a result of the bulky isobornyl groups. If the solution is diluted to 
$0.001 \mathrm{wt} \%$, the density of the deposits is reduced strongly, as expected, and the average distance between individual star molecules increases (see Supporting Info).

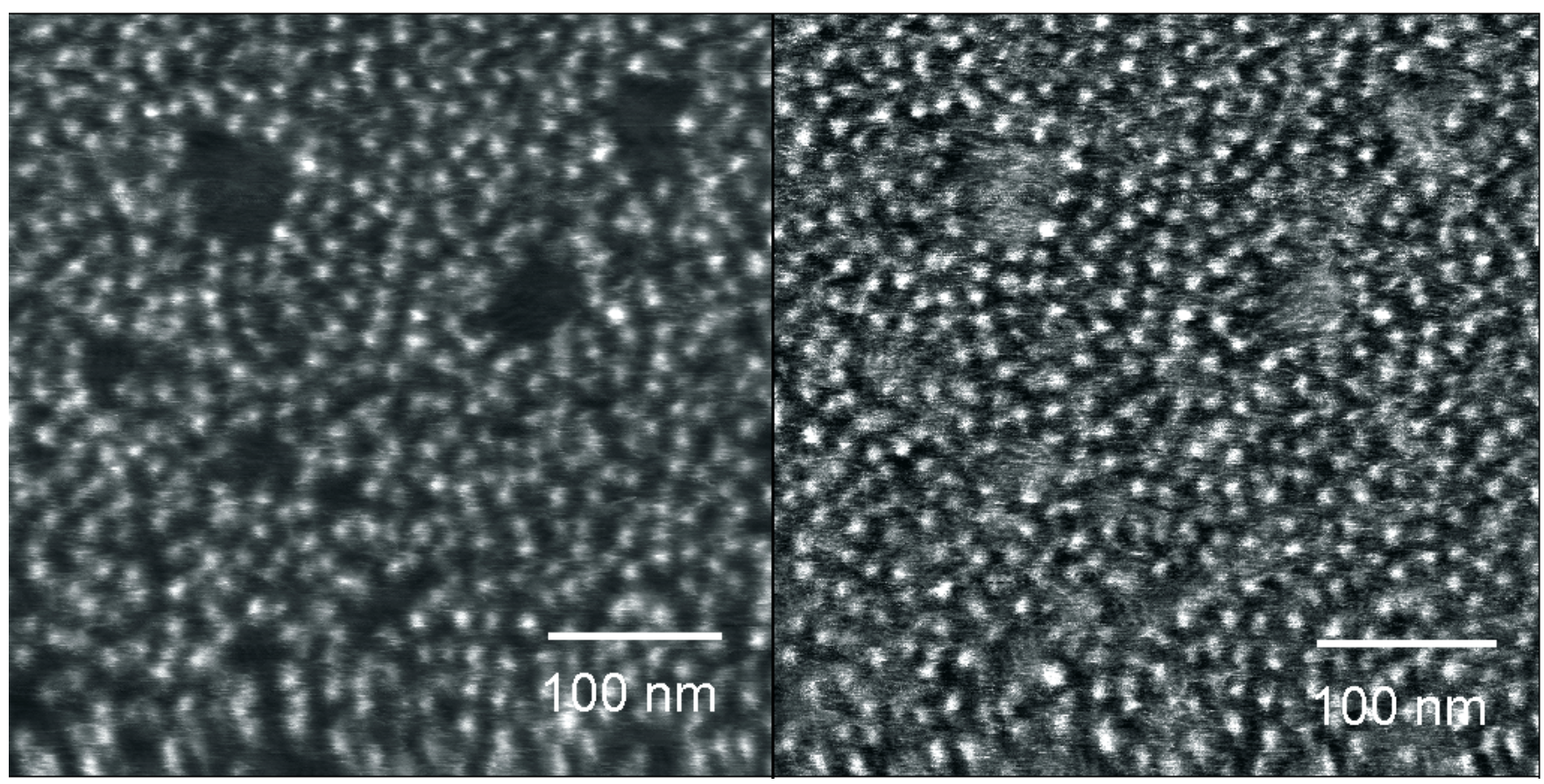

Figure $4: 400 \times 400 \mathrm{~nm}^{2}$ height (left) and phase (right) AFM images of a thin deposit of

PiBA_12A_7 (prepared from a solution of $0.05 \mathrm{wt} \%$ in THF).

\section{End group modification of poly(isobornyl acrylate)}

In a second step, the star-shaped PiBA was converted into a reactive star polymer (Scheme 1).

Methacrylate end groups have been introduced by a nucleophilic substitution of the end group using methacrylic acid according to a procedure described by Muehlenbach and co-workers ${ }^{39}$. This was one of the reasons why we opted for iBA as a monomer. For example, for poly(methyl methacrylate) no quantitative end group conversion was possible because of the presence of tertiary bromine end groups. 
In Figure 5, an example of a ${ }^{1} \mathrm{H}-\mathrm{NMR}$ spectrum of star-shaped PiBA modified with methacrylic acid is depicted. From the integration of the methacrylic protons (5.5 to $6 \mathrm{ppm}$ ), a conversion of greater than $95 \%$ was calculated. A broad range of samples with varying number of arms and molecular weight were prepared (Table 2).

The efficiency of the reaction was also monitored by MALDI-TOF. Because of the high molecular weight of the star-shaped samples, which inhibits the detection of individual star molecules, the analyses were performed on linear samples of low molecular weight. From Figure 6, which shows a part of the MALDI spectrum of such an end group modified linear PiBA-chain, it can be observed that all signals shift $5 \mathrm{Da}$ to lower mass due to the exchange of the bromine group by the methacrylate group. It can also be noted that there are three different series, in the starting material as well as in the modified polymer ${ }^{40}$. They all have a repeating frequency of 208 $\mathrm{Da}$, which is the exact molar mass of an iBA-unit. The main series corresponds with the expected structure. The two minor series cannot be readily explained. However, since they can be modified with a methacrylic group, they cannot be attributed to termination reactions in ATRP, because this would lead to loss of the bromine group. Impurities in the monomer probably cause the two additional signals.

To examine the diversity of the reaction, end group modifications with other acids than methacrylic acid were executed (see Table $2 \&$ Scheme 2). Surprisingly, the reaction with acrylic acid did not have the same efficiency as the reaction with methacrylic acid. Only at elevated temperatures and longer reaction times, some transformation (40\%, PiBA_12A_5_AA_3) was observed. However, this resulted also in side reactions that were detected by the appearance of shoulders in the SEC analysis (see supporting information). Cinnamic acid was also used as a 
nucleophile (see Table 2). This reaction was successful and conversions higher than $90 \%$ were reached (NMR in supporting info). In this way, reactive star-shaped polymers with a chromophoric group have been prepared, which could offer perspectives in UV-curable coatings.

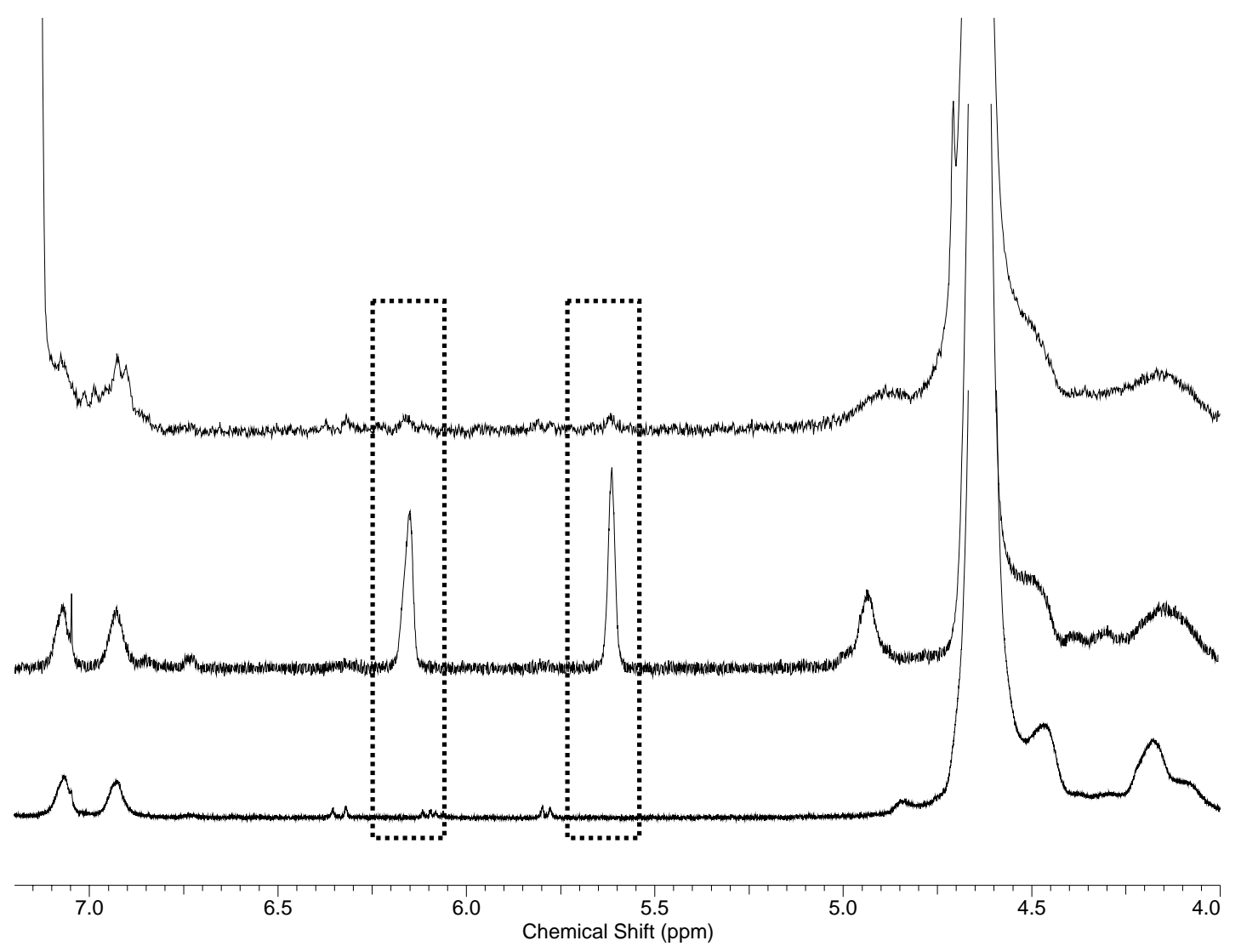

Figure $5:{ }^{1} \mathrm{H}-\mathrm{NMR}$ spectrum of PiBA_12A_10 (bottom), the methacrylate functionalized polymer (PiBA_12A_10_MA_1, middle) and the nanoparticle (12A_10_UV_4, top) (in $\mathrm{CDCl}_{3}, 500 \mathrm{MHz}$ ). 
Table 2: Reaction conditions and results of the end group modification of PiBA-star polymers

\begin{tabular}{ccccccc}
\hline Code & $\begin{array}{c}\mathbf{M}_{\mathbf{n}} \\
\left(\mathbf{g} \cdot \mathbf{m o l}^{-1}\right)\end{array}$ & Acid & $\begin{array}{c}\text { Ratio } \\
\text { acid/DBU }^{(\mathbf{a})}\end{array}$ & $\begin{array}{c}\text { Time } \\
(\mathbf{d a y s})\end{array}$ & $\begin{array}{c}\mathbf{T} \\
\left({ }^{\circ} \mathbf{C}\right)\end{array}$ & $\begin{array}{c}\text { Number of } \\
\text { reactive groups }\end{array}$ \\
\hline PiBA_12A_5_AA_1 & 59000 & AA & $2 / 2$ & 3 & 45 & - \\
\hline PiBA_12A_5_AA_2 & 59000 & AA & $4 / 4$ & 3 & 50 & - \\
\hline PiBA_12A_5_AA_3 & 59000 & AA & $4 / 4$ & 6 & 55 & 5 \\
\hline PiBA_12A_5_MA_1 & 59000 & MA & $4 / 4$ & 3 & 50 & 10 \\
\hline PiBA_12A_6_MA_1 & 34000 & MA & $4 / 4$ & 4 & 50 & 11 \\
\hline PiBA_12A_10_MA_1 & 44000 & MA & $4 / 4$ & 4 & 50 & 11 \\
\hline PiBA_6A_4_MA_1 & 10100 & MA & $4 / 4$ & 3,5 & 55 & 6 \\
\hline PiBA_4A_3_AA_1 & 7600 & MA & $4 / 4$ & 4 & 55 & 3.5 \\
\hline PiBA_12A_6_CA_1 & 34000 & CA & $6 / 6$ & 4 & 50 & 10 \\
\hline
\end{tabular}

Reactions done in ethyl acetate, AA: acrylic acid, MA: methacrylic acid, $\mathrm{CA}=$ cinnamic acid, $\mathrm{DBU}=1,8$ diazobicyclo[5,4,0]undec-7-ene, ${ }^{(a)}$ ratio compared to the number of bromine end groups; ${ }^{\left({ }^{b}\right)}$ number of bromine groups substituted to ester groups, determined by ${ }^{1} \mathrm{H}$ NMR. 


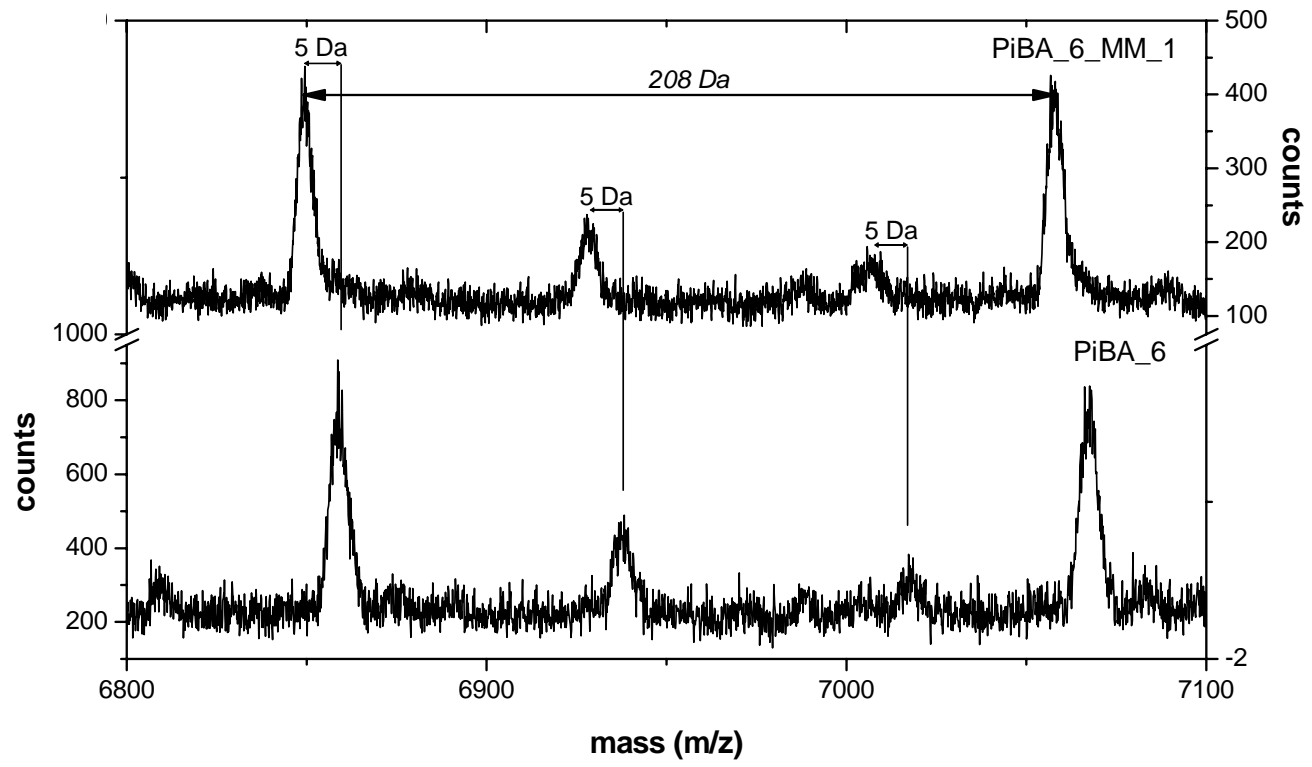

Figure 6: MALDI-TOF analysis of PiBA_6_MM_1 (bottom: start product PiBA_6, top: PiBA_6_MM_1).
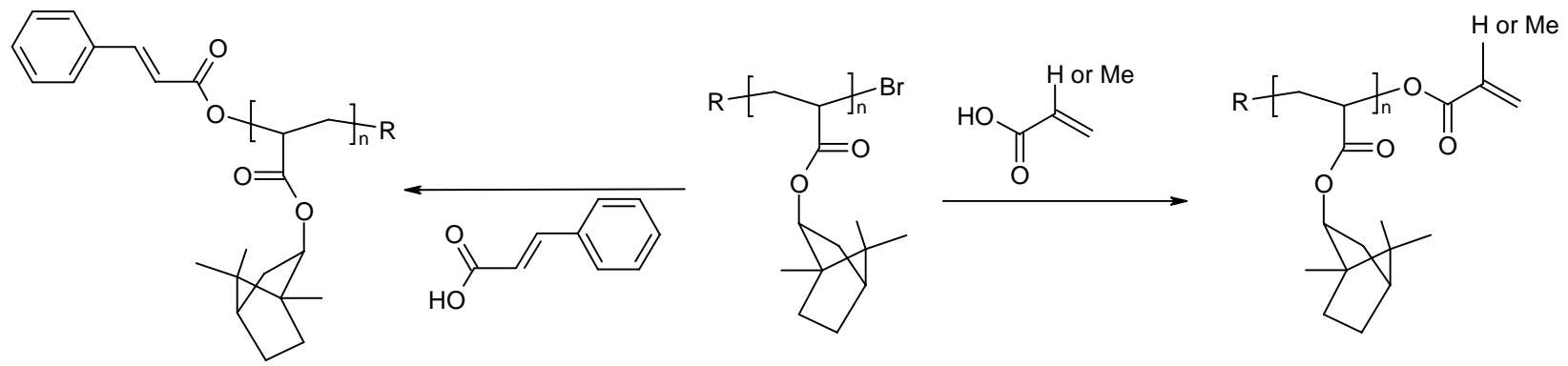

Scheme 2: End group modification of poly(isobornyl acrylate) with different acids (right: (meth)acrylic acid, left: cinnamic acid). 


\section{Nanoparticles from reactive star-shaped polymers}

Next, the methacrylate functionalized star polymers have been converted into nanoparticles by means of an intramolecular polymerization. Due to the lower reactivity of methacrylate groups bound to a polymer, UV initiation was chosen, resulting in shorter reaction times. An overview of a selection of reactions is given in Table 3. Since the ratio of inter- and intra- molecular reaction depends on the concentration of the polymer, a series of dilutions was examined. The resulting products were then analysed by NMR spectroscopy to determine the conversion and by SEC to detect the possible presence of coupled star polymers. As depicted in Figure 5 (top), the almost complete disappearance of the methacrylate signals demonstrate near quantitative conversion. Considering that the remaining methacrylate groups $(<10 \%)$ could participate in subsequent reactions, a couple of reactions including $\mathrm{Pt} / \mathrm{C}$ and $\mathrm{Pd} / \mathrm{C}$ catalyzed reductions to convert these methacrylate end groups into non-reactive groups have been performed. However, the NMR spectra (not shown) demonstrated that the remaining methacrylate groups survived the most stringent conditions, which confirms that they would interfere in the next stage of the research.

In Figure 7, the SEC analyses with triple detection for a polymer concentration of 50,15 and 5 $\mathrm{mg} / \mathrm{ml}$ are shown. The shoulders at high molecular weight, caused by intermolecular reaction, gradually reduce with decreasing concentration. At $50 \mathrm{mg} / \mathrm{ml}$, this shoulder spreads out over the whole measurable range of the SEC system. However, at $5 \mathrm{mg} / \mathrm{ml}$, only a small fraction of coupled product can be detected and the formation of cross-linked products can be excluded. Although a reduction of the concentration to an even lower value would finally lead to a pure product, a concentration of $4 \mathrm{mg} / \mathrm{ml}$ was selected for scale-up of the reaction in view of the determination of material properties afterwards. 
An important consequence when performing an intramolecular reaction on a star shaped polymer is the reduction of the particle size, resulting in a decrease of the chain mobility and the hydrodynamic volume. This reduction of the hydrodynamic volume of the nanoparticles, in comparison to the star-polymer, is illustrated in the SEC-curves presented in Figure 8. A clear peak mass reduction is observed in the SEC-chromatogram of the nanoparticles. Furthermore, by deconvolution of the chromatogram, an estimation of the amount of coupling products during the reaction could be made. For this analysis, a low value of $4 \%$ was calculated for the signal at double molar mass, which again shows the high efficiency of the intramolecular reaction. To our knowledge, this is one of the very few illustrations reported in literature where the end groups of star polymers are selectively reacted intramolecularly.

Table 3: Reaction conditions and results of the formation of PiBA-nanoparticles by means of an intramolecular polymerization.

\begin{tabular}{cccc}
\hline Code & $\begin{array}{c}\text { Conc. } \\
(\mathbf{m g} / \mathbf{m l})\end{array}$ & $\begin{array}{c}\text { Mol\% initiator } \\
(\mathbf{\%})^{(\mathbf{a})}\end{array}$ & Conversion (\%) $^{(\mathbf{b})}$ \\
\hline & PiBA_12A_8_Meth (see Table 1) & \\
\hline 12A_8_UV_1 & 50 & 20 & 95 \\
\hline 12A_8_UV_2 & 30 & 20 & 80 \\
\hline 12A_8_UV_3 & 15 & 20 & 90 \\
\hline & PiBA_12A_10_Meth (see Table 1) & network \\
\hline 12A_10_UV_1 & 900 & 20 & 80 \\
\hline 12A_10_UV_2 & 5 & 20 & 75 \\
\hline 12A_10_UV_3 & 4 & 20 & 80 \\
\hline 12A_10_UV_4 & 4 & 20 & \\
\hline
\end{tabular}

All reactions performed with UV initiation (using benzoin as initiator), reaction time: 4 hours in toluene.

(a) Mol\% initiator compared to methacrylate groups; ${ }^{(b)}$ determined by ${ }^{1} \mathrm{H}-\mathrm{NMR}$ 
(a)

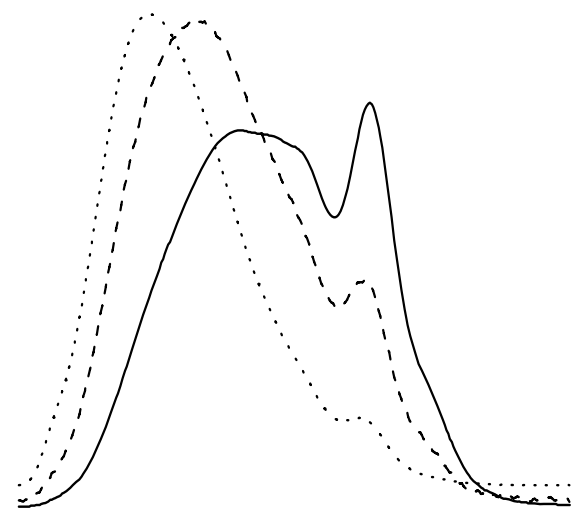

(b)
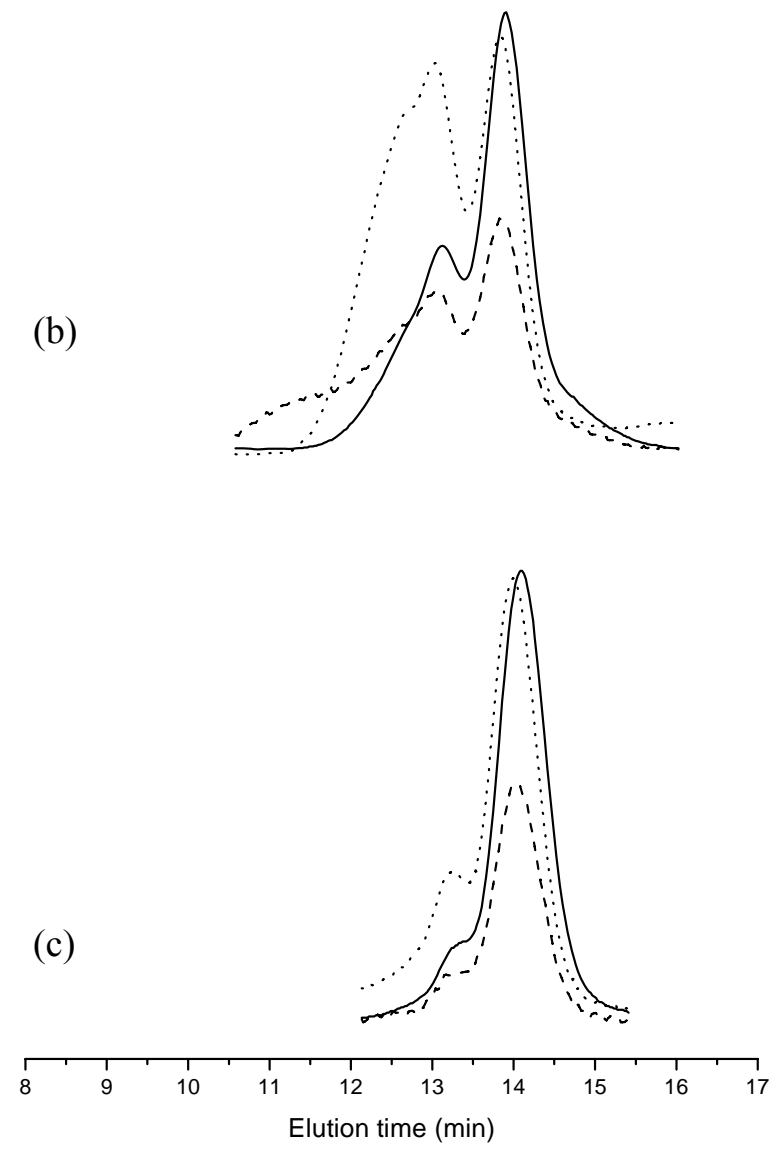

Figure 7 : SEC-analyses of the UV-reaction of methacrylate functionalized star-shaped PiBA at different dilutions: (a) $50 \mathrm{mg} / \mathrm{ml}$, (b) $15 \mathrm{mg} / \mathrm{ml}$ and (c) $5 \mathrm{mg} / \mathrm{ml}$. Different detectors were used (refractive index (-), viscosity (- - ) and light scattering $(\cdots)$ ). 


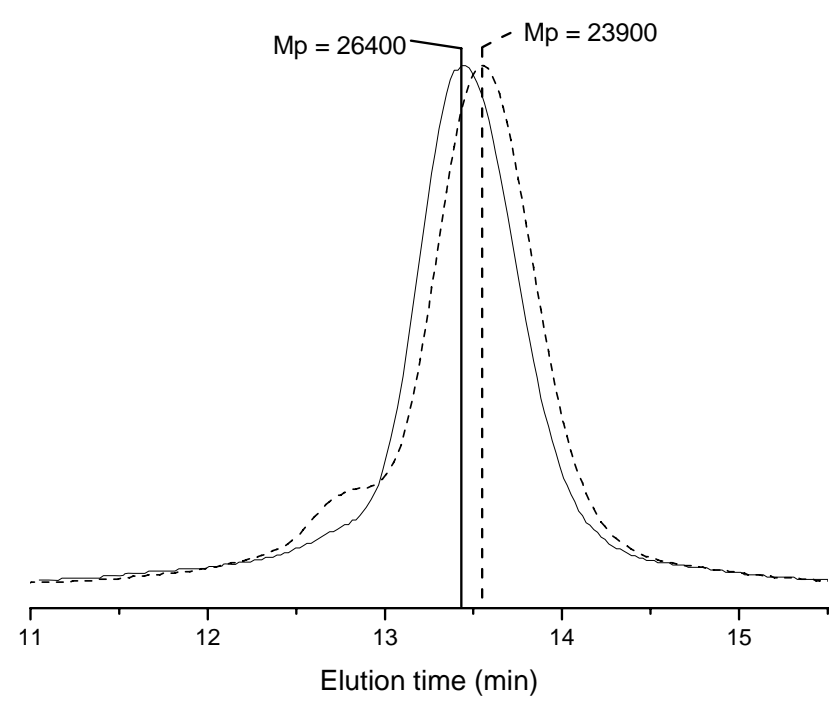

Figure 8: SEC-analyses of 12A_10_UV_4 (- -) and the star-shaped polymer ( - from which it was prepared $\left(\mathrm{M}_{\mathrm{p}}\right.$ : peak molar mass).

Polymeric nanoparticles as modifier for linear poly(n-butyl acrylate)

In a last step, the nanoparticles prepared by an intramolecular polymerisation at $4 \mathrm{mg} / \mathrm{ml}$ were examined as a viscosity modifier for linear PnBuA (see Scheme 1). By entanglement of the nanoparticles with linear polymers, it was expected that the physical properties should change, i.e., the addition of nanoparticles with a high $\mathrm{T}_{\mathrm{g}}$ to $\mathrm{PnBuA}$ with a low $\mathrm{T}_{\mathrm{g}}\left(-54^{\circ} \mathrm{C}\right)$ should result in a viscosity increase and a reinforcement of the material. On the other hand, as no entanglement is expected with the corresponding star polymers, these should not have a significant effect.

To create the entanglements, the PiBA-nanoparticles were dissolved in the monomer (nBuA), after which it was polymerized by a free radical polymerization with AIBN. An overview of the prepared materials is given in Table 4. Pure PnBuA and a material in which star shaped PiBA was added, instead of the nanoparticles, were also prepared as reference materials.

In Figure 9, the SEC curves (LS and RI detection) are depicted for PnBuA_blank, PnBuA modified with $5 \mathrm{wt} \%$ of bromine-terminated star shaped PiBA (PnBuA_M1) and PnBuA 
modified with $5 \mathrm{wt} \%$ of the nanoparticles (PnBuA_M3). A remarkable difference can be noticed between PnBuA_M1 and PnBuA_M3. While for PnBuA_M1, a signal attributed to the star polymer can be observed (at 13.5 min, indicated with the arrow), there is no such signal for the nanoparticles in the SEC-curve of PnBuA_M3. The absence of the signal of the nanoparticles proves their incorporation in the linear polymer as a result of chain entanglements. The fact that the star polymers (with bromine end groups) can still be observed separately also demonstrates that chemical cross-linking between the star polymers or nanoparticles, which might occur as a result of transfer reactions, is not occurring (or to a minimal extent). The dense star structure and the voluminous side groups of the PiBA chains can explain this absence of proton abstraction on the PiBA backbone. Recent studies have also demonstrated that the controlled character of the iBA homopolymerization can be maintained until high conversions ${ }^{40,41}$. In the case of the nanoparticles, the low fraction of remaining methacrylate end groups will also not participate in a reaction with $\mathrm{BuA}$, as explained earlier, confirming that the SEC observation can be ascribed to a non-covalent interaction only. It should be noted that, although a shift of the PnBuA signal to lower elution volumes (higher masses) could be expected in the presence of the nanoparticles, no interpretation of this signal can be made since the molecular weight of the PnBuA (made by free radical polymerization, $\mathrm{M}_{\mathrm{n}}$ about $400 \mathrm{kDa}$ ) was too high for the SEC-columns used. 


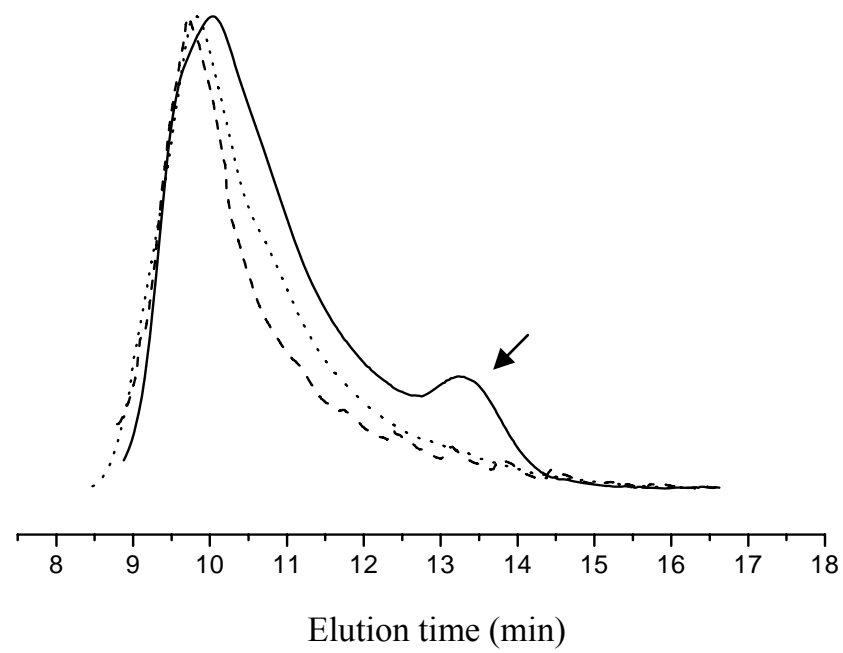

Figure 9 : SEC-analyses (LS-detection) of PnBuA_blank ( ‥), PnBuA_M1 (-), PnBuA_M3 ($--)$.

Finally, the mechanical properties of the modified PnBuA have also been examined by rheology measurements with a fixed stress and frequency as a function of temperature $\left(20\right.$ to $\left.130^{\circ} \mathrm{C}\right)$. From the values of the storage modulus (G'), the loss modulus (G') and the dissipation factor $(\delta)$, an indication of the change in the visco-elastic behavior of the different polymer materials is obtained. In Figure 10, $\delta$ as a function of temperature is depicted for the two reference materials and for PnBuA modified with $5 \mathrm{wt} \%$ of nanoparticles (PnBuA_M3). For pure PnBuA, $\delta$ increases with temperature as a result of the increasing chain mobility. If a star-shaped polymer is added to the PnBuA (PnBuA_M1), no change in this behavior is noted. However, if the PnBuA is modified with PiBA-nanoparticles, the $\delta$-value is clearly lower than for the blank sample and remains stable within the examined temperature range $\left(20\right.$ to $\left.130^{\circ} \mathrm{C}\right)$. Thus, the introduction of the nanoparticles drastically changes the visco-elastic behavior. Although the trends are clearly noticeable, it should be mentioned that the measurements in general contain some noise because 
the materials are quite tough, which result in the difficulty of handling the material in the rheometer.

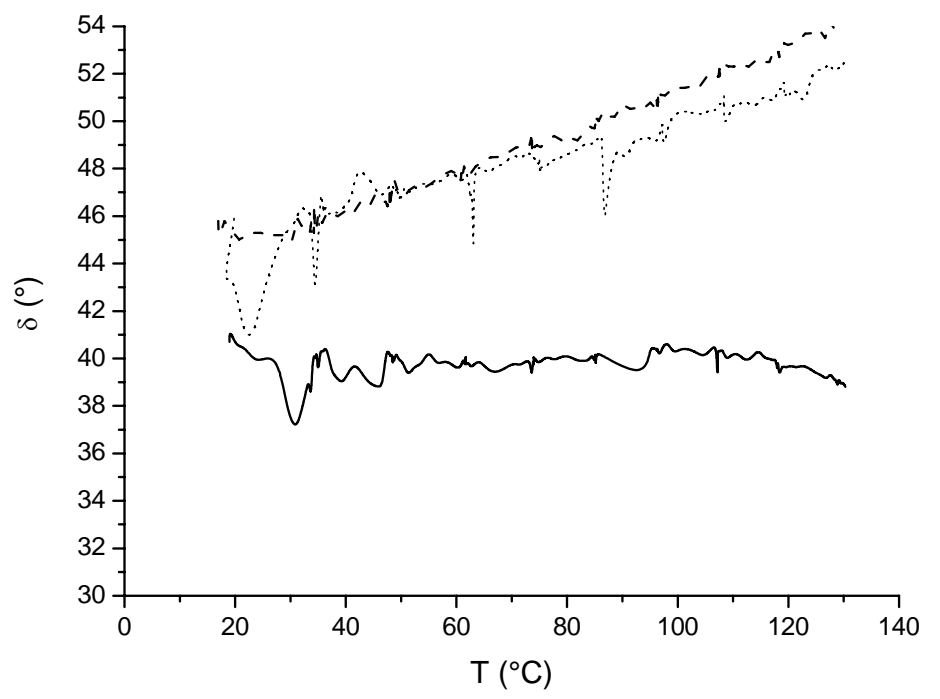

Figure $10: \delta$ as a function of temperature for PnBuA_blank ( $\cdots)$, PnBuA_M1 (- - -), PnBuA_M3 $(-)$.

Furthermore, it was examined to which extent the properties of $\mathrm{PnBuA}$ can be fine-tuned by changing the amount of nanoparticles. Different weight percentages (from 1 to 20\%) were added to $\mathrm{PnBuA}$ and the visco-elastic properties of the resulting materials have been measured. The result of these rheology measurements are summarized in Table 4. Again it is clear that the precursor star polymer cannot be used as an effective viscosity modifying agent. In contrast, by changing the ratio of nanoparticles, the properties of PnBuA can be specifically tuned as the resulting materials show an increased elastic behavior ( $\delta$ decreases) for increasing fraction of the nanoparticles. 
Table 4: Rheology results of PnBuA modified with PiBA-nanoparticles

\begin{tabular}{|c|c|c|c|c|c|c|c|}
\hline Code & Additive $^{(a)}$ & $\begin{array}{c}\mathrm{G}^{\prime}(\mathrm{MPa}) \\
\text { at } 40^{\circ} \mathrm{C}\end{array}$ & $\begin{array}{c}\text { G” (MPa) } \\
\text { at } 40^{\circ} \mathrm{C}\end{array}$ & $\begin{array}{c}\delta \\
\text { at } 40^{\circ} \mathrm{C}\end{array}$ & $\begin{array}{c}\mathrm{G}^{\prime}(\mathrm{MPa}) \\
\text { at } 80^{\circ} \mathrm{C}\end{array}$ & $\begin{array}{c}\text { G” (MPa) } \\
\text { at } 80^{\circ} \mathrm{C}\end{array}$ & $\begin{array}{c}\delta \\
\text { at } 80^{\circ} \mathrm{C}\end{array}$ \\
\hline PnBuA_blank & none & 5.2 & 5.4 & 46 & 1.7 & 2.0 & 50 \\
\hline PnBuA_M1 & $\begin{array}{l}5 \% \text { star } \\
\text { polymer }\end{array}$ & 7.1 & 6.8 & 44 & 2.5 & 2.7 & 48 \\
\hline PnBuA_M2 & $1 \%$ & 3.2 & 6.8 & 45 & 2.6 & 2.7 & 46 \\
\hline PnBuA_M3 & $5 \%$ & 9.3 & 7.0 & 37 & 4.0 & 3.2 & 38 \\
\hline PnBuA_M4 & $10 \%$ & 20.1 & 10.2 & 30 & 6.6 & 4.0 & 32 \\
\hline PnBuA_M5 & $20 \%$ & 20.2 & 10.3 & 29 & 8.3 & 4.7 & 29 \\
\hline
\end{tabular}

All measurements done with a tension of $5000 \mathrm{~Pa}$ at $3 \mathrm{~Hz}$.

(a) Weight percent PiBA-nanoparticles.

\section{Conclusion}

In this work, a new concept for the preparation of polymeric nanoparticles was developed. First, star-shaped PiBA polymers were prepared in a controlled way by ATRP. After end group conversion, the reactive star polymers were converted into a new type of nanoparticle by means of an intramolecular polymerization. It was clearly demonstrated that the incorporation of these nanoparticles in an acrylate polymer matrix can change the visco-elastic properties as a result of non-covalent chain entanglements.

\section{Acknowledgements}

Research financed by a Ph.D. grant of the Institute for the Promotion of Innovation through Science and Technology in Flanders (IWT-Vlaanderen). The Ghent-Mons collaboration is supported by the Interuniversity Attraction Poles program of the Belgian Federal Science Policy 
Office (PAI 6/27). Research in Mons is also supported by the European Commission and Région Wallonne (Phasing Out-Hainaut/Materia Nova), and FNRS-FRFC.

Supporting information available: NMR analysis of stars and nanoparticles, AFM images in dilute conditions, GPC analysis. This material is free of charge via the Internet at http://pubs.acs.org.

\section{References}

(1) Mishra, M.; Kobayashi, S. Star and hyperbranched polymers; Marcel Dekker Inc.: New York, 1999.

(2) Inoue, K. Prog. Polym. Sci. 2000, 25, 453-571.

(3) Matyjaszewski, K. Advances in controlled/living radical polymerization; American chemical society: Washington (D.C.), 2003.

(4) Matyjaszewski, K. Controlled/living radical polymerization; American chemical society: Washington (D.C.), 2000.

(5) Matyjaszewski, K. Controlled radical polymerization; American chemical society: Washington (D.C.), 1998.

(6) Kreutzer, G.; Ternat, C.; Nguyen, T. Q.; Plummer, C. J. G.; Manson, J. A. E.; Castelletto, V.; Hamley, I. W.; Sun, F.; Sheiko, S. S.; Herrmann, A.; Ouali, L.; Sommer, H.; Fieber, W.; Velazco, M. I.; Klok, H. A. Macromolecules 2006, 39, 4507-4516.

(7) Stenzel, M.; Davis, T. J. Polym. Sci.: Part A: Polym. Chem. 2002, 40, 4498-4512.

(8) Heise, A.; Hedrick, J.; Trollsas, M.; Miller, R.; Frank, C. Macromolecules 1999, 32, 231234.

(9) Heise, A., Nguyen, C; Malek, R.; Hedrick, J.; Frank, C.; Miller, R. Macromolecules 2000, 33, 2346-2354.

(10) Ueda, J.; Matsuyama, M.; Kamigaito, M.; Sawamoto, M. Macromolecules 1998, 31, 557562.

(11) Hovestad, N.; van Koten, G.; Bon, S.; Haddleton, D. Macromolecules 2000, 33, 4048-4052.

(12) Ohno, K.; Wong, B., Haddleton, DM J. Polym. Sci.: Part B: Polym. Phys. 2001, 39, 22062214.

(13) Huang, C.; Lee, H.; Kuo, S.; Xu, H.; Chang, F. Polymer 2004, 45, 2261-2269.

(14) Angot, S.; Murthy, K.; Taton, D.; Gnanou, Y. Macromolecules 1998, 31, 7218-7225.

(15) Wang, X. Z.; Zhang, H. L.; Shi, D. C.; Chen, J. F.; Wang, X. Y.; Zhou, Q. F. Eur. Polym. J. 2005, 41, 933-940.

(16) Beil, J.; Zimmerman, S. Macromolecules 2004, 37, 778-787.

(17) Zimmerman, S. C.; Zharov, I.; Wendland, M. S.; Rakow, N. A.; Suslick, K. S. J. Am. Chem. Soc. 2003, 125, 13504-13518.

(18) Zimmerman, S. C.; Wendland, M. S.; Rakow, N. A.; Zharov, I.; Suslick, K. S. Nature 2002, 418, 399-403. 
(19) Mecerreyes, D.; Lee, V.; Hawker, C.; Hedrick, J.; Wursch, A.; Volksen, W.; Magbitang, T.; Huang, E.; Miller, R. Adv. Mater. 2001, 13 (3), 208.

(20) Harth, E.; Van Horn, B.; Lee, V.; Germack, D.; Gonzales, C.; Miller, R.; Hawker, C. J. Am. Chem. Soc. 2002, 124 (29), 8653-8660.

(21) Hou, S. J.; Taton, D.; Saule, M.; Logan, J.; Chaikof, E. L.; Gnanou, Y. Polymer 2003, 44, 5067-5074.

(22) Cloutet, E.; Fillaut, J.; Astruc, D.; Gnanou, Y. Macromolecules 1999, 32, 1043-1054.

(23) Van Renterghem, L. M.; Goethals, E. J.; Du Prez, F. E. Macromolecules 2006, 39, 528-534.

(24) Antonietti, M.; Landfester, K. Prog. Polym. Sci. 2002, 27, 689-757.

(25) Capek, I.; Chern, C. S. In New Polymerization Techniques and Synthetic Methodologies 2001; Vol. 155, p 101-165.

(26) Wooley, K. L. J. Polym. Sci.: Part A: Polym. Chem. 2000, 38, 1397-1407.

(27) Wooley, K. L.; Hawker, C. J. Top. Curr. Chem. 2005, 245, 287-305.

(28) Jiang, X.; Luo, S.; Armes, S. P.; Shi, W.; Liu, S. Macromolecules 2006, 39, 5987-5994.

(29) Murthy, K. S.; Ma, Q. G.; Remsen, E. E.; Kowalewski, T.; Wooley, K. L. J. Mater. Chem. 2003, 13, 2785-2795.

(30) Butun, V.; Wang, X. S.; de PazBanez, M. V.; Robinson, K. L.; Billingham, N. C.; Armes, S. P.; Tuzar, Z. Macromolecules 2000, 33, 1-3.

(31) Miller, R.; Lee, V.; Connor, E. Abstr. Pap. Am. Chem. S. 2002, 224 part 2, 140.

(32) Holden, G.; Legge, N.; Quirk, R. Thermoplastic Elastomers; Hansen: Munchen, 1996.

(33) Ihre, H.; Hult, A.; Soderlind, E. J. Am. Chem. Soc. 1996, 118, 6388-6395.

(34) Ihre, H.; Hult, A.; Frechet, J.; Gitsov, I. Macromolecules 1998, 31, 4061-4068.

(35) Heise, A.; Diamanti, S.; Hedrick, J.; Frank, C.; Miller, R. Macromolecules 2001, 34, 37983801.

(36) Matyjaszweski, K.; Miller, P.; Pyun, J.; Kickelbick, G.; Diamanti, S. Macromolecules 1999, 32, 6526-6535.

(37) Walker, K. L.; Kahr, M. S.; Wilkins, C. L.; Xu, Z. F.; Moore, J. S. J. Am. Soc. Mass Spectr. 1994, 5, 731-739.

(38) Schriemer, D. C.; Li, L. Anal. Chem. 1996, 68, 2721-2725.

(39) Muehlebach, A.; Rime, F. J. Polym. Sci.: Part A: Polym. Chem. 2003, 41, 3425-3439.

(40) Dervaux, B.; Van Camp, W.; Van Renterghem, L. M.; Du Prez, F. E. J. Polym. Sci.: Part A: Polym. Chem. 2007, 46, 1649-1661.

(41) Van Camp, W.; Germonpré, V.; Mespouille, L.; Dubois, Ph.; Goethals, E.; Du Prez, F. React. Funct. Polym. 2007, 67, 1168-1180.

(42) Wouters, D.; Van Camp, W.; Dervaux, B.; Du Prez, F.; Schubert, U. Soft Matter, 2007, 3, 1537-1541. 
Graphic for use in the Table of Contents

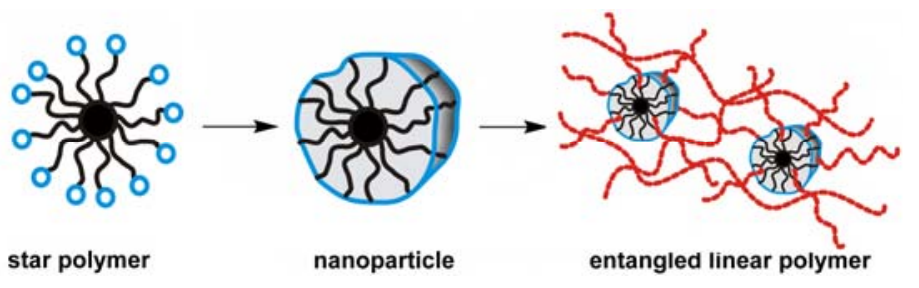

